\title{
Tell It Like It Is
}

\section{Patients as Partners in Medical Decision Making}

$\mathbf{M}$ any decisions in medicine require trade-offs. A test or treatment may reduce the likelihood of future morbid events, but at the cost of side effects and inconvenience. Thus, many diagnostic and treatment interventions require choices in which rational people might go either way. Increasingly, physicians and patients (now "consumers") recognize the need for patients to be involved in such decisions. Examples abound: hormone replacement therapy in post-menopausal women; many types of elective surgery; aggressive end of life care; and the conditions written about in this issue of the Journal: ischemic heart disease and anticoagulation for atrial fibrillation. ${ }^{1,2}$

Although we have long given lip service to the concept of informed consent, this typically takes the form of a physician recommending an option and then seeking patient endorsement. ${ }^{3}$ This is often fairly ritualistic and infrequently involves detailed discussion of various alternative management approaches; the expected benefits and risks of those options in quantitative terms; and enough information for patients to judge the desirability of various outcomes and treatment inconveniences. Some physicians may even feel they are abrogating their professional responsibility if they make no specific recommendation to patients, feeling that they are better informed, in most cases, than patients can be. However, patients may often value health outcomes and inconveniences differently than physicians, and each of us, as a patient, would like to make decisions maximally congruent with our own values. Although uninformed patient preferences may be relatively meaningless, well-informed preferences are essential for optimizing medical decisions.

Two studies in this issue of the Journal describe the current state of the art with regard to shared patient decision making. The study by Morgan and colleagues from Toronto describes a randomized trial of an interactive videodisc decision aid for patients with ischemic heart disease. ${ }^{1}$ This study demonstrates that a well-designed, state-of-the-art decision aid for patients can improve patient knowledge relevant to the decision and may help patients to clarify and express their preferences even if they disagree with those of their physicians. Patients chose less angioplasty or bypass surgery after viewing the video program than patients receiving usual care, but had equally good outcomes. Overall, patient satisfaction with the decision-making process was no different in the video group than the usual care group. ${ }^{1}$ The article by Man-Son-Hing and colleagues from Ottawa describes some of the practical issues involved in developing a highquality decision aid. It describes the background work that is relatively transparent in the Toronto study but is critical for developing an understandable and unbiased presentation. $^{2}$
One might quibble with methodologic details of these articles. One would have hoped for a lower dropout rate in the ischemic heart disease study, and some might have preferred disease-specific quality-of-life measures. One might argue with the precise probabilities chosen in the atrial fibrillation decision aid or believe that other factors should have been considered. Nonetheless, this pair of articles describes a sophisticated new approach to helping engage patients in their own medical care, and their messages are compelling.

These studies indicate the increasing sophistication and efficacy of patient decision aids. In both cases, the investigators have acknowledged that "one size does not fit all." The material presented to patients is tailored to their age, severity of illness, and co-morbidity, so that they see information that is as accurate as possible for their individual circumstances. Both decision aids have interactive features, and both use media other than print alone. The videodisc program for ischemic heart disease used video, computer graphics, and interactive computer technology. The atrial fibrillation decision aid made use of simple charts, graphics, and audio narration. Such tailored, interactive, and multi-media presentations seem more likely to engage patient attention and result in effective knowledge gains than print alone, and accumulating evidence supports this impression.

There are some formidable barriers to wider construction and use of such decision aids. Man-Son-Hing and colleagues allude to the lengthy process required to summarize the best scientific evidence, identify patients' key concerns, assemble multidisciplinary perspectives, pilot test and revise the program, and prepare the necessary materials for both patients and physicians. Evaluating the final program requires more time still. Although the study of Morgan and colleagues does not describe in detail the production costs for the ischemic heart disease program, it required production quality videotaping, narration and text development, computer graphics, and extensive programming to make the parts function together smoothly. This all followed a substantial effort to identify and summarize the best medical literature, interview researchers and clinical experts, and conduct focus groups with patients. Our experience in developing a similar videodisc program for back surgery (with the Dartmouthbased Foundation for Informed Medical Decision Making) ${ }^{4}$ demonstrated that such work can cost hundreds of thousands of dollars.

Keeping decision aids current is also a formidable task. The randomized trial of the interactive ischemic heart disease videodisc is being published in 2000, but the video program was constructed using the clinical literature published up to 1994, providing some indication of its age. The anticoagulation for atrial fibrillation decision 
aid may be newer, but the authors acknowledge recent publication of at least two major new studies that should be incorporated into future versions of the program.

There are other important barriers besides production costs. The use of such decision aids in clinical practice may require staff time and space, although one can easily imagine programs that most patients could employ in their own homes. How do we assure the objectivity and balance of the material presented to patients? It would be relatively easy to persuade patients into certain choices, and indeed this is the goal of the consumer marketing familiar to all. Patient decisions can be critically influenced by the manner in which information is framed, ${ }^{5}$ how it is presented, and what is presented. Thus, the producers of such programs have a moral obligation to present the information as impartially and informatively as possible.

Another barrier is criticism from the advocates of particular services or products whose utilization may be affected by well-constructed decision aids. If patients choose less surgery or less warfarin anticoagulation as suggested by the articles presented here, there will be winners and losers in the medical marketplace. Perhaps we should not be surprised that the articles originated in Canada, where a single-payer health system creates little incentive for supplier-induced demand. For similar reasons, such programs seem most popular in large staffmodel HMOs in the United States. It remains to be seen if such educational efforts can overcome the stream of directto-consumer advertising produced by the pharmaceutical industry, device manufacturers, and many health care providers. ${ }^{6,7}$

What can we say about the impact of this new generation of patient decision aids? Results of the randomized trial of the heart disease video are strikingly similar to the results of our recent randomized trial of a back surgery decision aid. ${ }^{8,9}$ In both trials, there was little change in patient satisfaction with the decision-making process, but patient knowledge of the relevant medical information was improved by the video programs, patients chose less surgery, and outcomes were just as good as those of usual care. The theme of greater knowledge gains is consistent with other studies, as is the apparent tendency of well-informed patients to choose less aggressive treatments than patients receiving usual care. Thus, for example, patients using carefully designed decision aids have chosen less prostate-specific antigen screening, ${ }^{10}$ less prostate surgery, ${ }^{11}$ less warfarin anticoagulation, ${ }^{12}$ less revascularization therapy, ${ }^{1}$ and less disc surgery than patients receiving usual care. ${ }^{9}$ Lest one conclude that these programs were written simply to reduce aggressive interventions, it should be noted that in every case the patient education materials were based on the best available medical literature, underwent evaluation by clinical experts, and were judged by both experts and patients to be well balanced. Furthermore, although the rates of disc surgery were reduced by the back pain video, there was a trend for more surgery among patients with spinal stenosis. ${ }^{7}$ Perhaps most important is the evidence that patients using these decision aids are more knowledgeable and are able to make decisions somewhat more independently than patients receiving usual care. ${ }^{1,9,13}$

What does the future hold for patient/consumer education? It seems certain that demand for information will remain high, and even greater momentum in this direction seems essential for both ethical reasons and market functioning. The World Wide Web may offer the ideal platform for providing such educational materials. Web-based decision aids could avoid the necessity of expensive hardware platforms, be inexpensively modified and updated, provide a high level of interactivity for patients, and be made available in both medical offices and in patients' homes. Based on the fragmentary evidence available so far, it seems these programs may reduce unnecessary care and perhaps unexplained geographic variations in care. However, the growth and success of these efforts will require the ongoing commitment of providers, researchers, and funding organizations to "tell it like it is" in an engaging and rigorous way.-RICHARD A. DEYo, MD, MPH, University of Washington, Seattle, Wash.

\section{REFERENCES}

1. Morgan MW, Deber RB, Llewellyn-Thomas HA, et al. Randomized, controlled trial of an interactive videodisc decision aid for patients with ischemic heart disease. J Gen Intern Med. 2000;15: 685-93.

2. Man-Son-Hing M, Laupacis A, O'Connor AM, et al. Development of a decision aid for patients with atrial fibrillation who are considering anti-thrombotic therapy. J Gen Intern Med. 2000;15:723-30.

3. Deber RB. Shared decision making in the real world. J Gen Intern Med. 1996;11:377-8.

4. Spunt BS, Deyo RA, Taylor VM, Leek KM, Goldberg HI, Mulley AG. An interactive videodisc program for low back pain patients. Health Educ Res. 1996;11:535-41.

5. McNeil BJ, Parker SG, Sox HC, Tversky A. On the elicitation of preferences for alternative therapies. N Engl J Med. 1982;306: 1259-62.

6. Bell RA, Kravitz RL, Wilkes MS. Direct-to-consumer drug advertising and the public. J Gen Intern Med. 1999;14:651-57.

7. Sauder R. Let (us help) the consumer beware! J Gen Intern Med. 1999; 14:705-6.

8. Phelan EA, Deyo RA, Cherkin DC, et al. Helping patients decide about back surgery: a randomized trial of an interactive video program. Spine. In press.

9. Deyo RA, Cherkin DC, Weinstein JN, Howe J, Ciol M, Mulley AG. Involving patients in clinical decisions: impact of an interactive video program on the use of back surgery. Med Care. 2000;38: 959-69.

10. Flood AB, Wennberg JE, Nease RF Jr., Fowler SJ Jr., Ding J, Hynes LM. The importance of patient preference in the decision to screen cancer. Prostate Patient Outcomes Research Team. J Gen Intern Med. 1996;11:342-9.

11. Wagner EH, Barrett P, Barry MJ, Barlow W, Fowler SJ. The effect of a shared decision making on rates of surgery for benign prostatic hyperplasia. Pilot results. Med Care. 1995;33:765-70.

12. Man-Son-Hing M, Laupacis A, O'Connor AM, et al. A patient decision aid regarding anti-thrombotic therapy for stroke prevention 
in atrial fibrillation. A randomized control trial. JAMA. 1999; 282:737-43.

13. Barry MJ, Cherkin DC, Chang Y, Fowler SJ, Skades S. A random- ized trial of a multimedia shared decision-making program for men facing a treatment decision for benign prostatic hyperplasia. Dis Manag Clin Outcomes. 1997;1:5-14.

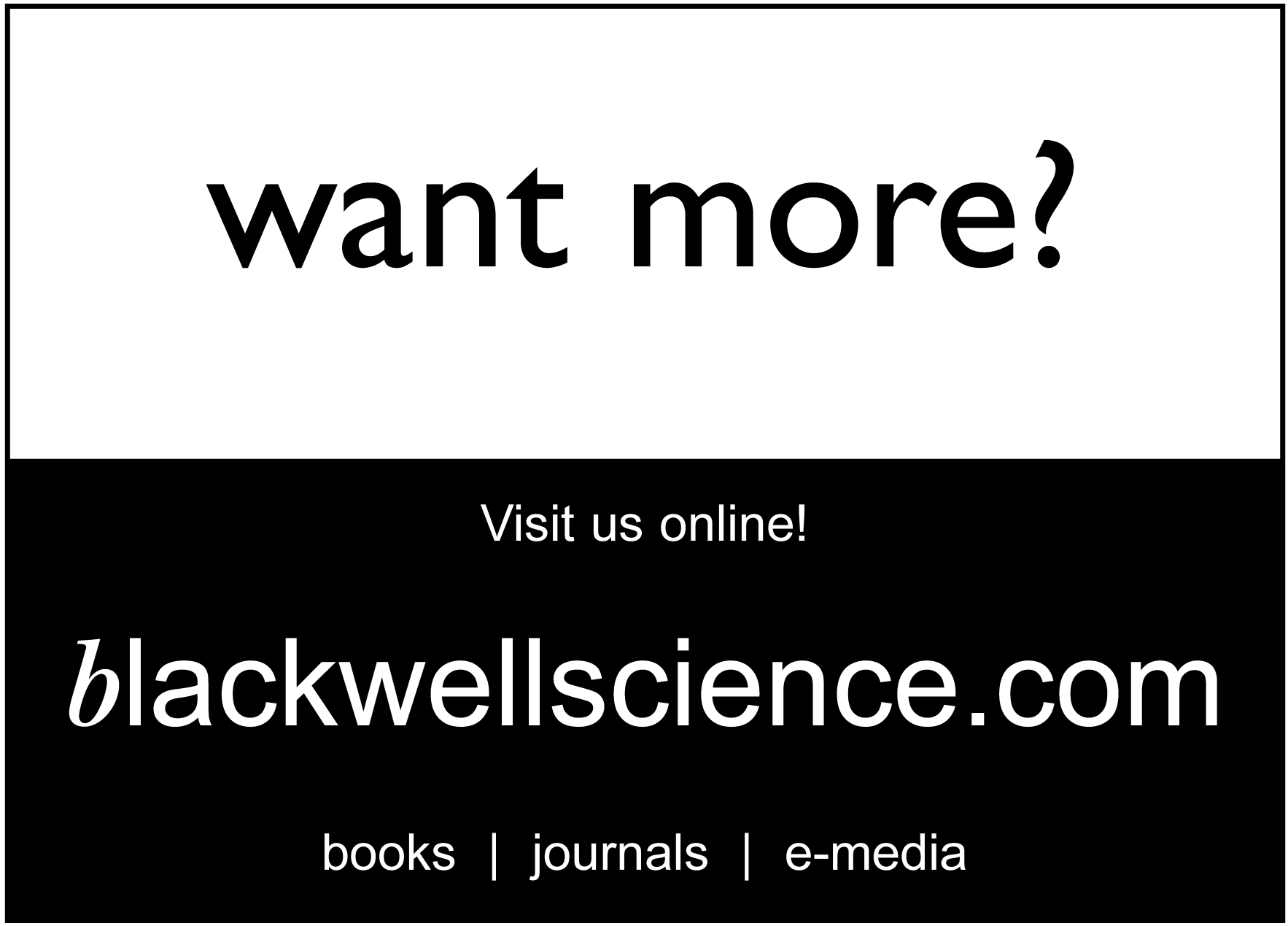

